\title{
Philosophy
}

http://journals.cambridge.org/PHI

Additional services for Philosophy:

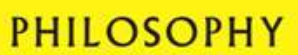

Email alerts: $\underline{\text { Click here }}$

Subscriptions: Click here

Commercial reprints: $\underline{\text { Click here }}$

Terms of use : $\underline{\text { Click here }}$

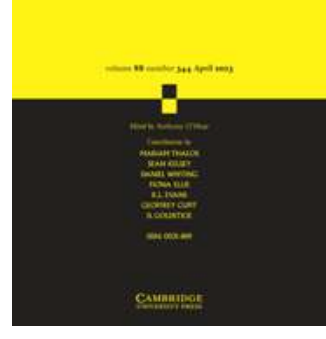

\section{Fraternity and Equality}

\section{Geoffrey Cupit}

Philosophy / Volume 88 / Issue 02 / April 2013, pp 299 - 311

DOI: 10.1017/S0031819113000089, Published online: 18 March 2013

Link to this article: http://journals.cambridge.org/abstract_S0031819113000089

How to cite this article:

Geoffrey Cupit (2013). Fraternity and Equality. Philosophy, 88, pp 299-311 doi:10.1017/S0031819113000089

Request Permissions : $\underline{\text { Click here }}$ 


\title{
Fraternity and Equality
}

\author{
GEOFFREY CUPIT
}

\begin{abstract}
Is there a connection between the values of fraternity and outcome equality? Is inequality at odds with fraternity? There are reasons to doubt that it is. First, fraternity requires us to want our 'brothers' and 'sisters' to fare well even when they are already better off than we are and their doing better will increase inequality. Second, fraternity seems not to require equality as a matter of fairness. Fairness requires (a certain) equality, but fraternity does not require fairness.

In examining what fraternity requires I discuss Rawls' suggestion that the difference principle corresponds to a natural meaning of fraternity, arguing that fraternity may be even more tolerant of inequality than the difference principle. Nevertheless, I defend the claim that fraternity and equality are linked, albeit not in such a way as to make inequality inconsistent with fraternity. Fraternity is related to equality since equalizing expresses the connectedness at the core of fraternity; but inequality is consistent with fraternity since there are other ways of expressing that connectedness.
\end{abstract}

\section{Introduction}

Is there a connection between fraternity and equality - where equality is understood as our lives going equally well in some significant sense? We might reasonably expect fraternal sentiments to be less common where there is significant inequality. But is there a connection between the values of fraternity and equality? Are the values themselves related? I want to argue that they are. But I also want to argue that the nature of this connection is not quite what we might expect - and for two reasons. First, the connection is not one that puts inequality at odds with fraternity. Fraternity and inequality are not incompatible. Second, although it is true that equality is a value in virtue of its being a constitutive element of fairness, equality's connection with fraternity seems not to rest on equality's being required by fairness. Thus, to the extent that fraternity provides a reason for valuing equality, that reason seems to be independent of the reason to value equality deriving from fairness.

Let me begin with a few words about fraternity and equality themselves, and the assumptions I will be making about them. Fraternity, 


\section{Geoffrey Cupit}

I will assume, is concerned with what we owe to each other on account of there being relationships between us - relationships of brotherhood, sisterhood, and fellowship. Fraternity requires benevolence: it requires us to want, and where appropriate to promote, the good of those who are our brothers, sisters, or fellows. But benevolence is not distinctive of fraternity since benevolence has other bases aside from fraternity. What we owe to others in virtue of fraternity is to be distinguished from what we owe on account of the kind of beings those others are, or in virtue of the qualities or characteristics those others have, or as a matter of reciprocity (for what others have done for us). Fraternal obligations are distinctive in being based on a specific type of relation or connectedness.

By 'equality' I will refer to outcome equality, that is, to our lives going equally well in some significant sense (measured in some appropriate way, and with whatever caveats are required). I shall assume - perhaps cavalierly - that whether there is a relationship between fraternity and outcome equality can be discussed without specifying the 'currency' in which equality is to be measured. In focussing on equality of well-offness I do not mean to imply that other types of equality cannot be connected to fraternity. It is simply that I wish to focus on the question of whether there is a connection between fraternity and outcome equality.

The values of fraternity and equality (in some sense at least) are often endorsed together - with people who believe in fraternity often believing in equality, and people who believe in equality often believing in fraternity. Both values occur (along with liberty) in the rallying cry of the French Revolution; both have an important place in socialist thought. Given such associations, it would be surprising if fraternity and equality were wholly unrelated. But my concern here is restricted to whether there is a particular kind of connection. Let me specify what that type of connection is.

As I suggested earlier, it seems reasonable to expect inequality to corrode fraternal sentiments - so that a sense of fellowship and brotherhood is less likely to flourish in the face of significant inequality. Inequality may strain our sense of being 'all in it together', our sense of being members of one 'family'. We may find it hard to empathise and identify with those much better off, or much worse off, than ourselves - thereby making it less likely that we will view others as our brothers or sisters. ${ }^{1}$ We might still care about those

1 It might be argued that inequality affects reality as well as perceptions - that it affects not only who I perceive as my brother (and thereby when I have, and may be moved by, fraternal sentiments), but also who is my 
who are less fortunate, but do so out of sympathy or pity, rather than from a sense of solidarity and brotherhood.

The significance of inequality undermining fraternal sentiments is hard to overstate. If a society is unequal, and sentiments of fellowship are undermined, we may expect instability; and with instability, many interests will go unsatisfied and many needs unmet. But important though this connection between fraternity and equality may be, it is not the kind of connection I wish to enquire about. Rather than asking whether fraternal sentiments are likely to survive in the face of inequality, I want to ask whether acting fraternally requires that we act so as to diminish inequality. More generally, I want to ask whether equality features in the specification of what it is to act fraternally. If it does, equality will be valuable not merely on the basis of useful effects.

The question of whether inequality is likely to undermine fraternal sentiments is in part a question about us - our natures and limitations. If we were saints, we might recognize and act on fraternal duties notwithstanding any inequality. Our empathy for others might not be strained by their being much better off than we are. To the extent that these are questions about us, they are questions to be addressed by empirical enquiry. The question I want to consider calls for a different type of enquiry. To ask what the requirements of acting fraternally are, and whether equality features in the specification of those requirements, is to ask whether equality is bound up with the nature of fraternity whether there is a link between the values of fraternity and equality themselves. To answer this question calls for philosophical enquiry.

It is not obvious that fraternity and equality are related. To see why this is so, and to set out the issue that needs to be addressed, I will begin with some reasons for doubting that fraternity and equality are connected.

\section{Connecting Fraternity and Equality: the Challenge}

In considering whether fraternity and equality are related, and whether fraternity is at odds with inequality, it is important to

brother. The inequality between a bourgeois and a proletarian, say, may be thought to undermine their being brothers (irrespective of whether they recognise that this is so or not). In this way inequality might limit not only fraternal sentiments and behaviour, but the scope of fraternity - how often the duties of fraternity are brought into play. 


\section{Geoffrey Cupit}

focus on equality and inequality - as distinct from considerations that are often present when there is inequality, but from which inequality is to be distinguished. It is important not to give inequality a bad name simply on account of the unfortunate company that inequality often keeps.

Frequently when there is inequality there are some who suffer significant and preventable deprivation; or there are some who take more than their share, and what rightly belongs to others; or there are some who are treated as inferior (when they are not). It is reasonable to say that acting fraternally requires that we do not ignore our brothers' significant and preventable deprivation, that we do not take what rightly belongs to our sisters, and that we do not treat our fellows as inferior (when they are not). But from the fact that such considerations are at odds with acting fraternally, it does not follow that fraternity is incompatible with inequality.

In order to focus on inequality - and to avoid being distracted by any of inequality's frequent associates - it is helpful to focus on cases where there is inequality but where the frequent associates are absent. (That such cases may be uncommon does not diminish their usefulness as aids to analytical reflection.) Let us suppose, then, that I have a sister who is worse off than I am. And let us suppose that the only alternative to our continuing with our current levels of welfare is a change that will make me better off but will leave her unaffected - neither better nor worse off. My becoming better off will increase the inequality between us. But it will not (let us suppose) involve my taking more than my share or what belongs to her; nor will it impose or continue a preventable deprivation; and nor will it amount to my treating her as inferior to me. Let us refer to cases such as this - cases where there is nothing other than a gratuitous advancement of the better off - as 'GABO cases'.

Is the increase in inequality in a GABO case at odds with the requirements of fraternity? Does fraternity require that we forgo improvements if we cannot share them with our sisters and brothers who are worse off? To act fraternally is to act in ways that respect and acknowledge the bonds between us. But does this require that we eschew courses of action that will increase the divergence in our respective fates? The issue here is not whether the demands of fraternity are sufficient to outweigh the desirability of increasing welfare, but whether fraternity calls for any forgoing of welfare in the first place. After all, fraternity requires not only the acknowledgment of our connectedness, but the acknowledgment of that connectedness with love and affection - in ways that reflect a desire that our brothers 
and sisters fare well. What sort of fraternity begrudges wellbeing for my brother simply because he is already more fortunate than I am? No doubt fraternal concern will increase as my sister becomes worse off absolutely, and decrease as she becomes better off absolutely. ${ }^{2}$ Thus fraternity will require more concern on the part of a better off brother for a worse off sister than it will require of a worse off sister for a better off brother. But why think fraternity is affected by inequality? Why think fraternity allows me to be less concerned about a disaster striking my brother simply because the disaster is also going to strike me? Fraternal affection is not, surely, the exclusive preserve of the better off. Why not think that it requires us to want the best for our brothers and sisters (other things equal), even if they are already better off than we are? If this is right, why think increasing inequality at odds with fraternity?

Is it possible to connect fraternity with equality by way of fairness to argue that fraternity requires fairness, and fairness requires equality? It seems not. It is true that equality is a constitutive element of fairness (and to that extent, fairness can require equality). But fraternity seems not to require fairness. It is not unfraternal to act in ways that increase unfairness. Or so I will argue.

To begin, let us consider the relationship between fairness and equality. Equality is a constitutive element of fairness. To illustrate, suppose that my sister is due (that is, deserves, or has a right to) 20 units of some good, and I am due 10. Suppose that these are all the dues we have. If 30 units are allocated, then fairness requires that my sister receives 20 units, and that I receive 10. Any other division would entail someone being denied what is due, and this would be unfair.

But suppose that 60 units of the good are to be allocated. What allocation is fair? If the dues really are as I have specified them (so what is due is an amount and not a share or proportion of the total being allocated; and while getting more than 20 or 10 is not something we are due, neither is it something we are due not to get), then the fair way to divide 60 is to allocate 35 and 25 respectively. Fairness requires that we each receive what is due (20 and 10 respectively); it also requires that where there is no difference in due, there should be no difference in allocation. Thus fairness (and I mean fairness, not justice) requires the equal allocation of the excess (there being no difference in due to

2 Egalitarianism (proper) is to be distinguished from prioritarianism the view that those doing less well (absolutely) have a stronger or prior claim - on the basis of its concern with the comparative. See Derek Parfit, 'Equality and Priority', Ratio 10 (1997), 202-221. 


\section{Geoffrey Cupit}

any of this excess). In sum, then, my sister receives her 20, plus an additional 15, while I receive my 10, plus an additional 15 .

Thus fairness requires equality: equality of (any) excess. But does fraternity require fairness? Suppose my sister and I are each due 20 and receive 20; but that it is possible for me, but only me, to receive an additional 10. My receiving this excess, and my sister not, produces an outcome that is less fair than the outcome where neither of us receives any excess. Does its being less fair mean that my receiving the excess would be contrary to fraternity? Surely not. What sort of fraternity is it that would have me telling my better off brother that it would be better if he did not become any better off since his becoming better off will increase unfairness between us? It would seem, then, that although fairness requires equality, fraternity does not require fairness. If this is so, then we cannot connect fraternity with equality by way of fairness.

How might we explain why fraternity does not require fairness? (The question here concerns fairness per se. Fraternity is, of course, incompatible with many arrangements that are unfair.) A plausible explanation is simply that fairness (that is, fairness per se) is not very important. Inequality of excess is unfair in virtue of being arbitrary (in a way that equality of excess is not); it is disorderly (with respect to due). But such arbitrariness and disorderliness seems not to matter very much. First, it is questionable whether such arbitrariness and disorderliness per se matter very much at all; second, it is questionable whether one more bit of arbitrariness and disorderliness (with respect to due) matters much in a disorderly world. Thus it seems reasonable to say that unfairness per se (as distinct from certain types of unfairness, and as distinct from injustice) does not matter very much. (This is why we often feel able to ignore our children's complaints of unfairness. Often they are right that arrangements are unfair, but wrong in the significance they ascribe to that unfairness.) And if unfairness does not matter very much, it will not defeat the presumption in favour of welcoming increases in welfare deriving from the requirement of fraternity to promote the welfare of our brothers and sisters.

\section{An Argument Connecting Fraternity and Equality}

I have suggested that GABO cases constitute a challenge to anyone who wishes to argue for a connection between fraternity and equality. Since fraternity requires us to want our fellows to fare well, it seems to require us to welcome increases in welfare in GABO cases 
notwithstanding the increase in inequality. It seems, then, that fraternity does not require equality. Ought we to infer that there is no link between the values of fraternity and equality?

I want to argue that fraternity and equality are connected, and I want to begin this argument by considering the passage in $A$ Theory of Fustice where Rawls suggests that the difference principle is a way of institutionalizing fraternity. Rawls writes:

No doubt fraternity does imply [a certain equality of social esteem ... and ... the absence of manners of deference and servility], as well as a sense of civic friendship and social solidarity, but so understood it expresses no definite requirement. We have yet to find a principle of justice that matches the underlying idea. The difference principle, however, does seem to correspond to a natural meaning of fraternity: namely, to the idea of not wanting to have greater advantages unless this is to the benefit of others who are less well off. The family, in its ideal conception and often in practice, is one place where the principle of maximizing the sum of advantages is rejected. Members of a family commonly do not wish to gain unless they can do so in ways that further the interests of the rest. ${ }^{3}$

Rawls suggests, then, that the difference principle can be seen as capturing a plausible understanding of what fraternity requires. It is worth noting that Rawls' claim requires a particular interpretation of the difference principle. The requisite interpretation is one according to which there is to be equality unless an unequal distribution is to everyone's advantage (or, at least, to the advantage of some who have less). This interpretation is to be distinguished from that which Rawls refers to as the 'lexical difference principle' which requires a maximizing from the bottom up - thereby allowing inequalities from which the worse off gain nothing. ${ }^{4}$ (It is, presumably, this second version of the difference principle that would be preferred in the original position by anyone motivated by mutual disinterest and a wish to do as well as possible.)

John Rawls, A Theory of Fustice (Oxford: Oxford University Press, 1971), 105. My discussion of the difference principle will be limited to its relationship with the requirements of fraternity. I make no comment on whether the difference principle is to be accepted as a principle of justice, except to say that the fact (if it is a fact) that the difference principle captures the requirements of fraternity, is not a reason to think that it satisfies the requirements of justice.

Ibid., 82-3. 


\section{Geoffrey Cupit}

It might seem perverse to focus on GABO cases in a discussion of Rawls. After all, it is hardly likely that improvements for the better off will have no effect whatsoever on those who are worse off. And indeed, in most of his discussion Rawls states the difference principle in such a way as not to address what is to happen in GABO cases. The difference principle is taken as requiring that the worst off be made as well off as possible. This way of understanding the difference principle is offered by Rawls as a simplified form of the lexical difference principle - the simplification being possible since chain connection and close-knitness are assumed. ${ }^{5}$ And with chain connection and close-knitness there are no GABO cases; thus the question of what is to happen when there are can be ducked. But focussing on GABO cases in assessing Rawls is not so perverse - since even if there are few or no GABO cases, there can surely be cases that come pretty close. And where one stands on GABO cases is likely to indicate where one stands on 'near GABO' cases - and thus on whether the difference principle (in any of its interpretations) captures, or is consistent with, the requirements of fraternity.

Suppose one thinks that gratuitous improvements for the better off are contrary to fraternity. In this case one may be expected to think that the difference principle errs on the side of being too lax in its identification of what is compatible with fraternity. The difference principle permits large increases for the better off if this is what it takes to make even a small improvement for the worse off. But if one thinks gratuitous improvements for the better off are at odds with fraternity, then one may be expected to object to improvements where the better off get a lot, and the worse off just a little. If, as a family member, I am concerned about an arrangement that benefits only me, oughtn't I also to be concerned about an arrangement that is hugely beneficial to me, but which delivers only small improvements to other members? If this is right, then those who reject gratuitous improvements for the better off as contrary to fraternity might reasonably think the difference principle too lax in its operationalizing of fraternity. It licenses too much. It allows, as not contrary to fraternity, large improvements for the better off that provide only small improvements for the worse off.

What of those who think fraternity allows gratuitous improvements for the better off? Those who take this view may well think the difference principle too strict in identifying what fraternity allows. Suppose the better off could be made significantly better off, but only by making the worse off a little worse off. If one thinks

5 Ibid., 82-3. 
gratuitous improvements for the better off are not contrary to fraternity, then one might be inclined to go a step further and say that if the improvement for the better off is big enough, and the loss to the worse off small enough, then the change is not at odds with fraternity. If fraternity involves a desire that others do well, including a desire on the part of the worse off that the better off do well, then perhaps it permits arrangements where the worse off make a small sacrifice so that the well-being of the better off can be much improved.

Thus there is reason to focus on GABO cases and whether they are, or are not, at odds with fraternity. What we think fraternity requires or precludes in these cases seems likely to be a touchstone for other cases - and for assessing whether the difference principle is too strict or too lax as a way of institutionalizing the requirements of fraternity.

Are improvements in GABO cases consistent with fraternity? Such improvements increase 'the sum of advantages' - indeed they are Pareto-optimal. But are they fraternal? What reason is there to think they are not? Why does Rawls consider them at odds with fraternity? His concern is not that such changes increase inequality (though of course they do). If inequality were the issue, then arrangements that significantly increase inequality but which satisfy the difference principle would also risk being at odds with fraternity and Rawls does not think that they are. So what does he think is contrary to fraternity about gratuitous improvement for the better off?

Rawls invites us to focus on the wants of the better off. The better off do not want to gain in ways that do not benefit others. The point concerns connectedness. The better off do not want to advance alone: they do not want to advance unless others advance too. Fraternity is about connection - it is about our being connected to those who count as our brothers and sisters. Gratuitous improvements for the better off are indicative of a lack of connectedness between us. Given that GABO cases are possible, 'loose-jointedness' and lack of 'close-knittedness' ${ }^{6}$ are facts of life. Our fates are not tightly bound up together: some may flourish while others do not. But allowing gratuitous improvements for the better off realises, and gives expression to, this lack of connectedness.

But are gratuitous improvements for the better off at odds with fraternity? Rawls is surely right to suggest that the better off, if they are to take their fraternity seriously, will have qualms about becoming better off in ways that leave the position of the less well off unimproved. Certainly they must regret that there is no possibility of

6 Ibid., 80. 


\section{Geoffrey Cupit}

shared advance. But, as I suggested earlier, the worse off will also have wants if they are to take their fraternity seriously. The worse off will need to want the better off to become even better off in GABO cases. Fraternity requires our wanting the best for all our brothers and sisters (other things equal) - including those who are already better off than we are.

The upshot, then, is a lack of congruence between desires in GABO cases: the better off will have a reluctance to become any better off than they are; the worse off will want the better off to become even better off. This lack of congruence derives from fraternity being concerned with connection. In GABO cases the good of the different parties does not advance together. This lack of collective advance raises the question of how the fraternal connection is to be actualized and expressed. For the worse off that question is answered by their wanting the well off to become better off. The increase in inequality is beside the point; connectedness is realised for the worse off by their wanting the good of their fellows. However, for the better off the position is different. There is no going forward together; there is an increase in inequality; and it is the better off's own good that is being advanced. For the better off, then, there is no affirming of the connectedness that is constitutive of fraternal relations. Indeed the increasing inequality is, prima facie, indicative of disconnection.

But this is not the end of the matter. The worse off can come to the aid of the better off - and surely, if the worse off are to take their fraternity seriously, must do so. My sister can assure me (should such assurance not already be understood) that she wants my becoming better off. Now there is a sense in which I also want to become better off. Were it not for concerns appertaining to fraternity, I would wish to become better off (or so we may suppose). Thus my becoming better off will be something we both want. And to the extent that it is a shared want, its satisfaction is able to mark our connection. I may express reservations about my having what my sister cannot also have. She will urge me to accept it, assuring me that my having it is something she wants. I may say: 'Are you sure?' She will assure me she is - that it is something she wants. I may wonder if this is so. But, in a number of ways, I will think ill of her if I do not think she does have this desire. I will think her unloving and that she does not take our fraternal relations seriously. And if I believe that, were our positions reversed, I would want her to become better off, then I will think her worse than myself if I believe she does not desire my good. Thus I may set aside my qualms about becoming better off (while still regretting that we are not advancing together) and become better off - accepting it on the basis of its 
being our shared desire whose fulfilment respects and affirms our connectedness. ${ }^{7}$

My suggestion, then, is that we ought to reject the view that gratuitous improvements for the better off are at odds with fraternity. It is true that the better off should have qualms about becoming even better off in GABO cases. But given a context in which fraternity is taken seriously, such qualms will be assuaged. And further, if my earlier analysis was correct, it would seem that the difference principle is not too lax in laying out the requirements of fraternity. Given that fraternity allows gratuitous improvement for the better off, there seems no reason why it should not also permit large increases for the better off where these are necessary to produce small increases for the worse off. Indeed the difference principle may be too strict as a specification of what is consistent with fraternity. Given that fraternity permits gratuitous improvements for the better off, it might be thought that it also permits (perhaps even requires) small sacrifices by the worse off where this is necessary to achieve significant benefits for the better off. (Such sacrifices will, of course, need to be brought about in the right way if they are to be consistent with fraternity. But again, a failure by the worse off to do what is necessary to render the sacrifice consistent with fraternity might be thought to bring into question whether continued acknowledgement of our supposed connectedness is appropriate.)

So what about the relationship between fraternity and equality? Does equality play any role in relation to fraternity? Rawls suggests that a way to operationalize fraternity is the difference principle. The difference principle is willing to licence any degree of inequality so long as the position of the worst off is improved. The principle invites us to focus on those who have less - but not with a view to reducing inequality. The objective is to make the worse off better off (absolutely). When Rawls tells us where liberty, equality, and fraternity are looked after in his theory he does not suggest that the difference principle looks after equality. Rather he says:

7 It is true that I might still have had reason to set aside my qualms about becoming better off even if my sister had wanted me not to. Where fraternal love is unrequited, we might wonder if the connection is one to take seriously. But this does not make her wanting immaterial - making no difference to the situation. My becoming better off may be right both when my sister wishes it and when she does not; but what makes it right in the case where she wishes it will be quite different to what makes it right where she does not. 


\section{Geoffrey Cupit}

... we can associate the traditional ideas of liberty, equality, and fraternity with the ... two principles of justice as follows: liberty corresponds to the first principle, equality to the idea of equality in the first principle together with equality of fair opportunity, and fraternity to the difference principle. ${ }^{8}$

Now I have not accepted the difference principle as a way of operationalizing fraternity. But my argument has not been that the difference principle takes inequalities as consistent with fraternity when in fact they are not. Rather, I have argued for the reverse: that fraternity permits more inequalities than the difference principle allows. I have claimed that gratuitous improvements for the better off are not contrary to fraternity (even though they create inequalities that the difference principle prohibits). And I have even suggested that fraternity may permit large improvements for the better off at the expense of small sacrifices for the worse off - again a way of increasing inequality that is beyond the pale as far as the difference principle is concerned.

So is inequality simply irrelevant as regards fraternity? Is there no link at all between fraternity and equality? I want to suggest that equality does matter - and in the following way. I have focussed on GABO cases. But now consider what we may call 'GAWO cases' cases where there is gratuitous advancement of the worse off. Now surely the gratuitous advancement of the worse off is not at odds with fraternity. But why is this? There is no going forward together: the advance is gratuitous - leaving others unaffected. Now I have argued that gratuitous improvements for the better off are not at odds with fraternity. But it would be preposterous to explain the consistency of improvements in GAWO cases with fraternity in the way that I have explained the consistency of GABO cases with fraternity. The worse off need have no qualms about their advancing, and need no assurance from the better off that their advance is wanted. And the reason this is so is because in GAWO cases the improvement reduces inequality. It closes the gap, and its doing so is a way by which connectedness may be expressed.

My suggestion, then, is that fraternity and equality are linked - but not in such a way as to make inequality at odds with fraternity. Fraternity and equality are linked in that equalising is one of the ways by which the connectedness that is constitutive of fraternity may get actualized and expressed. But our connectedness may be affirmed in other ways - ways that may increase inequality. It may be

8 Ibid., 106. 
expressed by our all advancing (with those who do least well being made as well off as they can be made). Such arrangements may increase inequality; but their doing so does not make them at odds with fraternity. Another way of actualizing or expressing our connectedness is by an improvement for just some of us being accepted on the basis of its being a shared goal. Again such an improvement may result in an increase in inequality; but that it does so is not a reason to think the advance at odds with fraternity (although it may, of course, have a tendency to discourage fraternal sentiments).

\section{Conclusion}

I have argued that equality is connected with fraternity. This connection seems not to go by way of fairness since fraternity seems not to require fairness. (Thus equality's value as a means of affirming fraternal connection seems distinct from its value as a constitutive element of fairness.) Fraternity's link with equality rests on the role equality can play in affirming and expressing the interpersonal connectedness that is central to fraternity. But since equality is but one of the ways of affirming our connectedness, we should resist the temptation to infer that inequality is, in itself, at odds with fraternity. ${ }^{9}$

GEOFFREY CUPIT (cupit@waikato.ac.nz) teaches political philosophy at the University of Waikato, New Zealand. He is a previous contributor, the author of Justice as Fittingness (Oxford University Press, 1996), and currently works on fairness and equality.

$9 \quad$ I have presented material included here, or earlier versions of this paper, at the International Philosophy Conference on Liberty, Equality, Fraternity, Uludağ Üniversitesi, Bursa, Turkey (2010); the Australasian Association of Philosophy (NZ) Conference, University of Waikato, Hamilton, New Zealand (2010); the $22^{\text {nd }}$ World Congress of Political Science (RC31), Universidad Complutense de Madrid, Madrid, Spain (2012); and at seminars at the University of Liverpool, the National University of Ireland, Galway, and the University of Stirling. I am very grateful for the comments I received on those occasions. 